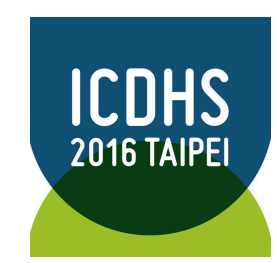

\title{
Design Transformation:
} The effect of global change and the reconceptualization of design in Mexico and Latin America since the 1980's

\author{
Oscar Salinas-Flores / National Autonomous University of Mexico / \\ Mexico City / Mexico
}

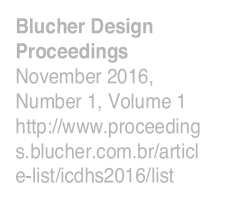

\begin{abstract}
What is it that defines design in a country facing the phenomena that led to significant worldwide changes in the 21 st century? This document analyses the impact of cultural, social and technological transformations from the 1980's in the design discipline and the consequences generated in the profession's development in the first years of the 21 st century. In an increasingly changing and complex world, design has reconceptualised, creating new profiles in the professional practice of design and generating change in disciplinary training. As a response to these changes, the design profession has set new limits in its relationship with society, and is faced by the ambivalence of whether attending social priorities and emergencies, or responding to the countless production of goods that are flooding the world through globalized markets. How has this situation affected Mexico and Latin America, and how has this region responded to the transformations being faced in the 21 st century? If we were to see design as a system that interacts with the socio-economical, political and cultural environments, its response shows us three different general situations. These identify this discipline in the region and its impact in society within and beyond it's borders.

This text shows the change in design from the historiographical and phenomenological perspective, and explores a prospective analysis on the future of the discipline from the study of the transformations that are building the new paradigm of design in this century.
\end{abstract}

\section{Keywords}

Design transformation, new paradigms, historiography, phenomenology, Mexico and Latin America

\section{Introduction}

During the course of its history, design has never been as restless and vibrant as today. The relationship between human beings and objects or services is increasingly closer and the expansion of the conception, production and marketing of products involving a design process is becoming profounder and more widespread in the developed world. In the second half of the 20th century, a phenomenon of change that was linked to social, technological and scientific transformations came to happen. It significantly changed the geopolitical and cultural development of most nations in the international environment, and this in turn had an impact on the training and the professional practice of designers. During the 1980's, a significant number of contributions occurred in the social, technological and scientific domains, all of which would eventually give rise to what some philosophers of contemporary life, such as Gilles Lipovetsky have called hipermodernism: a development with increasing consumption and new lifestyles in "an open-minded society, characterized by movement, fluidity, flexibility and detachment from the great underpinning principles of modernity", typical of the years lived so far during this century (Lipovetsky, 2006)

\section{The drivers of change}

Interestingly, in the 1980's, a series of events which seemed to be loosely connected came about. They were the breeding ground for new multifaceted designs that would later meet the requirements of a changing world and never before manifested.

\section{How did this process of change start?}

After World War II, the victorious nations lead to a global realignment that generates two main blocs: the Soviet 
socialism and the capitalist countries of the West, a situation that, one way or another, has an influence on the development of almost every country in the world and gives way to the cold war, during which the leaders of the two sides try to gain central control of the international environment.

In the Western world, globalization processes are stimulated. Consequently, a growing interconnection is triggered, both on communication and interdependence, but most importantly, new markets are produced and mimicked around the world, imposing an increasing number of brands of items and services, which have been a means of disseminating and achieving a culture of control that has had an impact on almost all urban societies in the world, thus, changing lifestyles, likes, aspirations or identities, and leaving behind the values that once prevailed during twentieth-century modernity.

Today, it is possible to identify the facts that had the most relevant impact on design in the 1980 's. For example, in 1981, IBM, one of the most innovative companies worldwide at that moment, introduces the first PC (personal computer), which would transform the modes of communication and intellectual output in our world.

Likewise, in the United States, from the 1960's onwards, the first works in order to develop a human communication network through computer devices, the Internet, are initiated, but it is not until the 1980's that this new form of global communication is consolidated, a time in which the protocols and languages, used to date, are finally incorporated. In 1986, the method and devices to produce an object by printing successive layers of a plastic material, stereolithography, are introduced. Actually, this technology has continued to evolve into what is now commonly called three-dimensional printing. From the moment the Macintosh computer is launched, the production of digital images and typography prompts the planning work of designers, who could use this technology for domestic purposes for the first time.

In 1989, based on their observations of the earth, NASA space research informs about global warming, and this also brings about various actions to combat its impact on humanity. As a result, designers had this situation in mind when planning their future career goals.

Furthermore, towards the end of 1989 , as a symbol of the fall of communism, the Berlin Wall is smashed to pieces, and the dismantling of the Soviet Union also takes place, a country that, throughout that decade, had suffered from a breakdown in structure, a serious economic stagnation and the collapse of the ideological values that once had held that system. This situation gives way to a new world order, so new markets for designers emerge.

Like never before, the use and quick progress of the Internet helps designers work by means of the new access to information, and instantaneous connection to a world vaguely known opens new career prospects for designers.

\section{Design transformation}

21st-century design has rapidly been changing areas of expertise, and today it is palpable how professionals have addressed new areas of work. By 1990, Richard Buchanan, one of the most renowned authors of design philosophy, had already thought about the new career fields that designers had begun to get involved in, he called them 'specialized research fields' (Buchanan, 1995). From the early 20th century, the first two areas that had traditionally been addressed were design integrated to symbolic and visual communications, historically associated with graphic design; and secondly, design of material objects, mainly related to the profession of industrial design.

However, towards the end of the 20th century, the fields of design linked to organized services, complex systems and new living environments were increasingly present.

These new ways of dealing with design are a reflection of the changes occurring. They created a segmentation of the profession which gave way to new profiles for designers, who have gotten over the circumstances imposed by both, new technologies and social change.

These are some professional subdivisions worth mentioning:

- Universal Design

- Interaction Design / interface design

- Experiential Design

- Emotional Design

- Participatory Design

- Design for Sustainability

- Service Design

- Co-Creation / Co-Design

These changes have reconceptualised design. In fact, they have had such an impact that academic institutions and 
professionals have been made to reassess their relationship with society.

\section{What have been the ways and modes of operation of designers?}

Concerns about climate change, overexploitation and deterioration of the ecological environment and the marginalization of a large number of inhabitants of the planet has motivated some designers to act in order to participate in the solution of these problems, and, metaphorically speaking, a door has been opened to facilitate their work. Today, a growing number of designers around the world have the chance to interact and work together - every day - with others via the Internet. Independent designers have learned to work with NGOs, sponsors, international political organizations or active social groups to get resources and other kind of support so as to carry out their projects without having to act only with the help from productive industries, as happened in the 1980's; promoting what today is recognized as participatory design or co-design, and giving additional meaning to their professional work.

The inclusion of new technologies in designers' work has significantly changed their work and it has revolutionized and transformed the design process; from concept to production and even marketing. Digitizing projective information, using numerical control machines and equipment such as three-dimensional printers have all allowed the development of customized product design.

Undoubtedly, design has expanded dramatically and it has thus changed the boundaries of the profession. Today, it is no longer enough for many designers to conceive a new item for an average consumer $-\mathbf{a}$ marketing term which they increasingly prefer to use less - , so they focus on those groups of citizens who suffer from a certain problem or need, and conceive experiences emphasizing emotions, and, as a result, they achieve the desired consumer satisfaction.

The 21 st century displays increasingly complex projects, made possible by a techno-science that has reached unpredicted limits, such as nanotechnology, presented today at the cutting edge of tomorrow's world and supported by a new material culture that might change the standards of life for humankind.

Likewise, a growing number of designers are participating in the projection of complex systems that are created for new life forms. They may range from James Dyson's sophisticated appliances to communication products like those by Apple-Macintosh, or to increasingly complex devices, such as wearables, which are aimed at improving the quality of human life.

All this has led to a change in the preparation of designers. Hence, academic institutions have sought to adapt or modify their curricula, their didactic resources, their academic tasks, and even the name of their majors. They have been in need of linking or merging the knowledge and experience coming from students, integrating specialties or areas of knowledge in a single institution, thus achieving a better response to the changing needs of society.

\section{Impact on Latin America}

In Latin America, this phenomenon of change impacted professional design significantly. Before the introduction of these new technologies, the design of the region was out dated, compared to that of many developed countries, mainly in Europe and North America. Two issues essentially caused the difference: lack of access to inside information and lack of proper skills in advanced technology. However, globalization came to facilitate access to both. In fact, using the Internet decreased the isolation of developing countries by promoting synchronous international communication and thus generating a dynamic exchange of information that had an influence on the training and professional development of designers. This same process enabled access to new technologies, since the globalization of trade and the international advertising of materials as well as equipment for production and specialized software all helped reduce the gap between the less and the more developed regions.

Considering the aforementioned situation is key to understand why, Latin American designers have increased their contributions and more awards have been won in recent years, once deficiencies from the past were dealt with.

During the early 1960's, design as an area of knowledge started almost simultaneously in Mexico, Brazil and Argentina, when the first university courses in design were created. In Mexico, graphic design started from a long tradition of graphic arts, which gathered an extensive collection of artistic expressions. On the other hand, industrial design came without an established industrial base or a culture of innovation that rendered this new discipline necessary. Eagerness from Mexican architects was core for the founding of this new profession and so was the presence of a generation of pioneers of furniture design, mostly emigrants from other countries, who, be- 
tween 1930 and 1960, developed high quality furniture using local materials and learned how to interpret a traditional culture with extensive experience dating back several centuries.

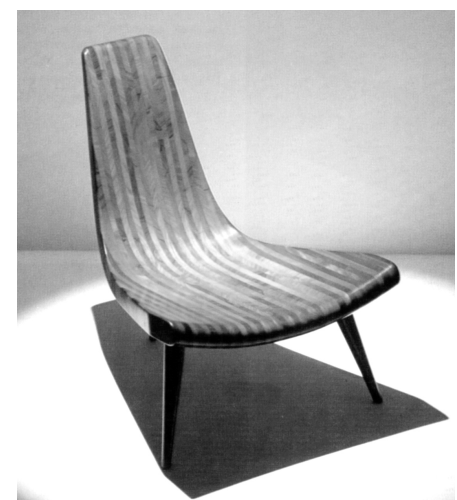

Fig. 1: Tripod chair, Joaquim Tenreiro, Brazil, 1947

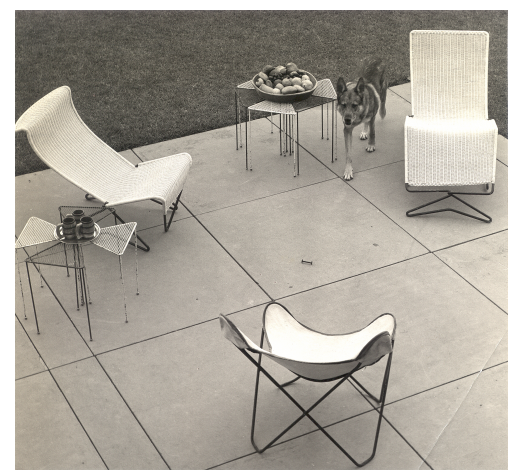

Fig. 2: Exterior chairs, Clara Porsel, Mexico, 1948

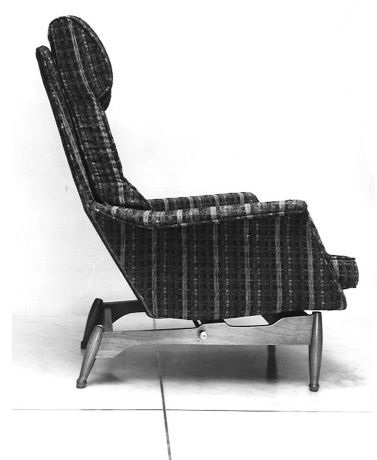

Fig. 3: Fiberglass armchair, Horaclo Duran, Mexico, 1960

The first generations of industrial designers, of which I was part, developed their practice by focusing on meeting the needs of producers of goods and their markets, rather than on the needs from citizens that were used to purchasing whatever a protectionist governmental tariffs policy had made available since the 1950's; a strategy allegedly beneficial to maintaining and fostering development of domestic industries.

The result was contradictory. In the absence of competition, innovation was subdued and a policy of copying and reproduction of already marketed products in more developed countries was stimulated. Additionally, the designer faced a local technological lag, where design information was accessible only through obsolete print media, thus, such technology was inadequate to design new proposals. As a consequence, so as to meet the needs of local markets, the talent of designers then focused on developing projects that were based on the use of intermediate technology and local raw materials and, at its best, it was geared towards developing import-substituting products, or occasionally, an improved patent.

This situation began to change from the 1990's, when the phenomenon of transformation that this analysis is addressing finally started.

\section{What were the key factors that triggered this transformation?}

An important factor is the opening of vast new markets for products designed

Social changes such as the collapse of the Soviet bloc and the redefinition of political and cultural objectives in China and rising commodity prices in developing countries, such as Latin America and the Middle East, generated classes with greater procurement capacity, better quality of life and an aspiration to live in a new culture of global consumption, influenced by new media interconnected via satellite and fibber optics.

\section{The second factor is the unlimited use of communications}

The broad global communications and international agreements between geopolitical regions has meant that designers in Latin America internationalize, thus they have become quite proficient in English and other languages; with academic or research stays in other countries, and postgraduate studies that rank them practically on par with designers in developed countries.

\section{The third factor is access to new technologies}

New technologies, new forms of communication and new information management have increased the number of designers who act as entrepreneurs, who are associated with independent interdisciplinary and international groups and are working on projects abroad. An important component has been the steady decline in the prices of production equipment, such as three-dimensional printers, and new materials, which allow its use with little investment.

\section{The fourth factor is political and government support}

Also, the new development policies of government systems have generated actions such as expanding academic offerings and evaluation and rewarding good university programs. This has meant that countries such as Mexico and Brazil have significantly increased the number of schools for the training of designers and the number of graduate courses ( $90 \%$ of doctors throughout Latin America are educated in these two countries). Similarly, higher research resources have accelerated the development of design disciplines. Furthermore, designers from this region have recently understood how to participate in integrative concepts like "creative economy" or "cultural economy", both of which having included design as a factor for their progress. 
The 2008 and 2010 reports on creative economy, and the 2013 UNCTAD Special Report, among others, show sustained growth in the sector since 2003, and it has been more resistant to the impact of the global economic crisis than traditional manufacturing industries.

The report indicates that Mexico has a share of $1.3 \%$ in the global creative market. In 2008, the country reported an annual growth in exports of creative products of $9.1 \%$ over 2003 , and ranks eighteenth in the world, the first in Latin America and the fifth among developing countries.

Today Mexico is expected to consolidate its dominance as the main exporter in Latin America and the Caribbean and might increase its share in total exports of the region from $34.3 \%$ in 2013 to $41.1 \%$ in 2015 , according to the CEPAL (Economic Commission for Latin America and the Caribbean). It may be added that the participation of Mexico may increase, even though its exports recorded an inter-annual fall of $4 \%$ in 2015 , since the region as a whole showed a decline of $14 \%$ in foreign sales.

The sum of all these factors have led to a new outlook for some countries in Latin America, where Brazil - a country exceeding 200 million inhabitants - despite recent downsides, ranks as the best positioned due to production and marketing of products designed inside and outside their borders and the production of professional designers.

Mexico - a country with 122 million inhabitants - has a high number of design schools -nearly 90 of them focus on industrial design, and at least 120 are related to graphic design - with a large domestic consumer market, but still scarce in regards to exports of manufactured goods created by its designers, despite the positive export figures I have previously mentioned.

Designers have diversified their work extending the scope of the discipline in Latin America. Along with Brazil and Mexico, after leaving periods of political uncertainty, founding members of the discipline in the region such as Argentina and Chile have begun to consolidate their development and have staked out a development based on innovation and markets for social benefit. Behind them, Colombia, Ecuador, Uruguay, Peru, and Cuba make design an increasingly respected discipline by participating in transcendent projects, leaving behind its image of undervalued technical occupation with artistic pretensions, and subjected to other professions such as architecture or engineering.

\section{Conclusion}

From what I have discussed, I could well say that this process of change and evolution emerged during the 1980's, and today, about 35 years later, in a world characterized by change and the rate of change, as never before, Latin America has benefited from circumstances that gradually and under pressure - from the affected countries, in a globalized world -, have left behind colonization and dependency, as we knew them in late modernity, to make way for a new economic and cultural relationship, where design has much to say.

\section{References}

Ander-Egg, E. (2004) Repensando la Investigacion-Accion Participativa. Buenos Aires: Lumen.

Campi, I. (2013) La historia y las teorías historiográficas del diseño. Mexico: Designio.

Exhibition's catalog of Bienal Brasileira de Design, (2010) Curitiba: Centro de Design Paraná.

Exhibition's catalog of Brasil Faz Design. 2002. Sao Paulo: SEBRAE.

Frias, J. (ed.) (2012) De la creavidad a la inovación. 200 diseñadores mexicanos. Mexico: Diseña/Mexico, ITESM / Designio.

Giron, H. (ed.) (2015) Catálogo de la exhibición 'Bienal Nacional de Diseño', Mexico: Conaculta, Escuela de Diseño INBA.

Julier, G. (2010) 'Mas allá de las fronteras', in Diseño e Historia, Tiempo lugar y discurso, Mexico: Designio. Lipovetsky, G.(1986) La era del vacío. Barcelona: Anagrama.

- (2004) Los tiempos hipermodernos. Barcelona: Anagrama.

Margolin, V. \& Buchanan, R. (eds.) (1995) The idea of Design, Cambridge / London: MIT Press.

McLuhan M. \& Powers, B.R. (1992) The Global Village: Transformations in World Life and Media in the 21st Century. Oxford: Oxford University Press.

Narotzki, V. (2010) 'Los límites de lo perfecto: nuevos paradigmas del diseño y la cultura material', in Diseño e Historia, Tiempo lugar y discurso, Mexico: Designio. 
Salinas, O. (reimp 2009). Historia del Diseño Industrial. Mexico: Trillas.

Thackara, J. (2006). In the Bubble, Designing in a complex world. Cambridge/ London: MIT Press.

http://noticias.universia.net.mx/vida-universitaria/noticia /2012/02/22/913127/brasil-mexico-tienen-90doctores-graduados-america-latina.html

http://unctad.org/es/Docs/ditctab20103_sp.pdf

http://eleconomista.com.mx/industrias/2015/10/21/mexico-eleva-su-dominio-exportador-latinoamerica

\section{Biographical note}

Oscar Salinas-Flores is the researcher and professor at the National Autonomous University of Mexico, with 40 years of experience. He combines professional practice, research and teaching. One of he's main lines of research is the history of design, he is author of multiple publications in books and magazines focused on design disciplines. 